\title{
EL CONVENIO DE OVIEDO Y SU ADECUACIÓN A LAS NUEVAS TÉCNICAS DE INTERVENCIÓN DEL GENOMA HUMANO
}

\author{
JOAQUÍN JIMÉNEZ GONZÁLEZ \\ Médico Adjunto, Servicio de Urgencias. \\ Hospital Rafael Méndez, Lorca (Murcia) \\ Doctor en Derecho \\ joaquinjg@msn.com
}

\begin{abstract}
RESUMEN: El Convenio de Oviedo, habiendo supuesto un avance esencial en el derecho internacional de consenso en materia de derechos humanos y biomedicina, veintitrés años después necesita adecuarse a los nuevos avances científicos respecto a las técnicas de intervención de la línea germinal humana. Aceptando que éstas forman parte ya del contexto social, científico y jurídico de nuestra época, y que alguna de ellas necesita aún un intenso debate sobre su aplicación, como las técnicas de edición del genoma, analizamos en el presente trabajo cuales son las modificaciones que consideramos oportunas para que la norma incluya esta realidad y ofrezca mayor seguridad jurídica respecto a estas técnicas.
\end{abstract}

PALABRAS CLAVE: Convenio de Oviedo, CDHB, biología, biomedicina, bioderecho, bioética, Consejo de Europa, TGP, preimplantacional, donación mitocondrial, CRISPR-Cas9, edición del genoma.

ABSTRACT: The Oviedo Convention, having supposed an essential advance of consensus in the international law in the matter of human rights and biomedicine, twenty-three years later needs to adapt to the new scientific advances regarding the techniques of intervention of the human germline. Accepting that this is already part of the social, scientific and legal context of our time, and that some of these techniques still need an intense debate on their application, such as genome editing techniques, we analyze in this work what are the modifications that we believe that they are necessary for this convention to include this reality and offer greater legal certainty regarding these techniques.

KEYWORDS: Oviedo Convention, biology, biomedicine, biolaw, bioethics, Council of Europe, PGD, preimplantation, mitochondrial donation, CRISPR-Cas9, genome editing.

SUMARIO: I. INTRODUCCIÓN. II. TÉCNICAS DE INTERVENCIÓN GENÉTICA HUMANA ASOCIADAS AL CAPÍTULO IV DEL CDHB. II.1 Test genético preimplantacional. II.2 Donación o reemplazo mitocondrial. II.3 Técnicas de edición del genoma. II.4 Otras técnicas. III. DisCusión RESPECTO AL CAPítUlo IV DEL CDHB. III.1 Artículo 11 CDHB. III.2 Artículo 12 CDHB. III.3 Artículo 13 CDHB. III.4 Artículo 14 CDHB. IV. ConCLUSIONES. V. BiBLIOGRAFÍA.

\section{INTRODUCCIÓN}

Seguramente el Convenio de Oviedo o, en su denominación exacta, el Convenio para la protección de los derechos humanos y la dignidad del ser humano con respecto a las aplicaciones de la Biología y la Medicina (Convenio relativo a los derechos humanos y la biomedicina, CDHB), de 4 de abril de 1997, es la norma que ha conseguido mayor grado de coordinación a nivel internacional respecto a la intervención del genoma humano. Fue adoptado para garantizar 
la dignidad de las personas y de sus derechos y libertades dentro del campo de la Biología y la Medicina. Su firma y ratificación es vinculante para el Estado que la realiza y, por tanto, obliga a su cumplimiento ${ }^{1}$.

Hoy día sigue siendo referencia jurídica dentro de la legislación supranacional relacionada con esta materia. Como manifiesta Marcelo Palacios, uno de los impulsores del convenio, constituye «una aportación primordial a la regulación de las actuaciones en los complejos campos de la Medicina y la Biología, al establecer un catálogo de principios éticolegales armonizadores de las aplicaciones científico-técnicas de aquellas disciplinas con la dignidad humana y los derechos y libertades de ellas dimanados» ${ }^{2}$. Gracias a esta norma, el Consejo de Europa fue precursor en el derecho internacional respecto a la biomedicina y los derechos humanos, al convertirse en el primer instrumento jurídico internacional vinculante que estableció criterios aplicables a la clínica asistencial y a la investigación e intervención del genoma humano. Algunos autores como Romeo Casabona se preguntan si el convenio supone el reconocimiento de nuevos derechos, ya que el CDHB revela la insuficiencia del marco general que existía respecto a los nuevos retos que presenta el campo de la biotecnología previo a su constitución, refiriéndose de forma específica a la Convención Europea de Derechos Humanos de $1950^{3}$. Según el autor, el convenio tiene un ámbito internacional-regional que parecía necesario para garantizar su aprobación y posterior eficacia, al encontrar una cierta homogeneidad cultural, social y jurídica entre los países miembros del Consejo de Europa que podrían ratificarlo. No obstante, su vocación es universal ya que, bajo condiciones no muy rigurosas, cualquier Estado podría firmar o ratificar el convenio.

No obstante resulta llamativo que, como expone el artículo $29 \mathrm{CDHB}$, la labor encomendada al Tribunal Europeo de Derechos Humanos (TEDH) se limite a «emitir dictámenes consultivos, con independencia de todo litigio concreto que se desarrolle ante un órgano jurisdiccional, sobre cuestiones jurídicas relativas a la interpretación del presente Convenio». Además, dicha tarea consultora solo puede ser realizada, según prosigue el artículo, por el Gobierno de una de las Partes del convenio, el Comité Director para la Bioética (CDBI), instituido por el artículo 32, o «por cualquier otro Comité designado a este efecto por el Comité de Ministros». Por tanto, a esta mera función asesora se une la imposibilidad ofrecida por parte del convenio a que cualquier ciudadano pueda acudir a instancias como el TEDH para reclamar que su Gobierno haga efectivos los derechos establecidos por el convenio ${ }^{4}$. Aunque es de suponer que para conseguir tan importante consenso debió ser necesario un ímprobo esfuerzo, a nuestro juicio el convenio no ofrece suficiente amparo jurisdiccional, seguramente por evitar una

\footnotetext{
${ }^{1}$ En España fue ratificado por unanimidad el 29 de abril de 1999, en Sesión Plenaria del Congreso de los Diputados. El 20 de octubre de ese año fue publicado en el Boletín Oficial del Estado, para finalmente entrar en vigor el 1 de enero de 2000.

${ }^{2}$ En PALACIOS, M. «La Convención o Convenio de Asturias de Bioética. Recordatorio y Comentarios», en la página web de la Biblioteca Jurídica Virtual del Instituto de Investigaciones Jurídicas de la UNAM: https://archivos.juridicas.unam.mx/www/bjv/libros/6/2673/5.pdf (consultado 18/11/2019).

${ }^{3}$ ROMEO CASABONA, C.M., «El Bioderecho y la Bioética, un largo camino en común», Revista Iberoamericana de Bioética, 2017, $\mathrm{n}^{\mathbf{o}} 3$, pp. 8-10, en la página web de la Universidad Pontificia de Comillas: http://revistas.upcomillas.es/index.php/bioetica-revista-iberoamericana/article/view/7658/7478 $\quad$ (consultado 18/11/2019)

${ }^{4}$ Sobre la cuestión diversos autores se han manifestado en el mismo sentido. Así, ROMEO CASABONA, C.M., «El Bioderecho y la Bioética, un largo camino en común», cit., pp 9-10, considera que la función otorgada por el convenio al TEDH ciertamente pobre, ya que hubiera sido deseable su competencia para conocer las infracciones al Convenio, de forma similar a la establecida para la Convención Europea de Derechos Humanos, aunque de todos modos no quede excluida la posibilidad de acudir al TEDH para solicitar tutela al amparo de éste último. Por otro lado, DE MIGUEL BERIAIN, I., LAZCOZ, G., «El Convenio de Oviedo, veinte años después de su firma. Algunas sugerencias de enmienda», Rio de Janeiro, 2018, vol. 11, $\mathrm{n}^{\circ}$ 1, p. 458, considera que el convenio debería introducir un capítulo dedicado a las consecuencias derivadas de su incumplimiento, si se quiere considerar esta norma como auténtico derecho, y no solo como una armonización de intenciones por parte de un conjunto de Estados.
} 
pérdida de soberanía nacional en estas cuestiones, lo que da una idea de la dificultad existente para la construcción europea en materia de lo social ${ }^{5}$. Así se refleja en el art. 1 CDHB, que establece la obligación de las Partes a proteger «al ser humano en su dignidad y su identidad», para a continuación dar potestad a cada Parte de adoptar «en su legislación interna las medidas necesarias para dar aplicación a lo dispuesto en el presente Convenio». Así, otorga a cada Estado definir su propia legislación en relación al estatus moral que le confiere al embrión ${ }^{6}$.

Otra particularidad de este convenio es sin duda el amplio refrendo. Efectivamente, el CDHB ha sido firmado por 35 de los 47 países que forman el Consejo de Europa, y ratificado por 29 , que como hemos dicho es la condición que vincula al país ${ }^{7}$. No obstante, es considerable que no lo hayan hecho países como Holanda e Italia. Otros ni siquiera lo han firmado, como Alemania, Reino Unido, Austria, Bélgica, Rusia, Malta o Irlanda, y las razones difieren sustancialmente dependiendo de cada Estado. Mientras que el Reino Unido consideró que el convenio es demasiado restrictivo, Alemania lo consideró permisivo, sobre todo en temas controvertidos como la investigación con embriones y la investigación no terapéutica ${ }^{8}$. En Austria, la Comisión de Bioética de la Cancillería Federal consideró que no firmar el convenio es una garantía para que el test genético preimplantacional (TGP) no condujera, en "pendiente resbaladiza", a la intervención genética de la línea germinal". Otros países no europeos intervinieron como observadores en la elaboración del Convenio, así como del Protocolo

\footnotetext{
${ }^{5}$ De hecho, otro documento del Consejo de Europa vinculado a la cuestión, como la Resolución legislativa del Parlamento Europeo, de 2 de abril de 2014, sobre la propuesta de Reglamento del Parlamento Europeo y del Consejo sobre los productos sanitarios para diagnóstico in vitro, en su considerando 67bis manifiesta la «política inveterada» de la Unión Europea de no interferir en políticas nacionales referidas a «aquellas tecnologías controvertidas desde el punto de vista ético, como las pruebas de diagnóstico genético preimplantacional».

${ }^{6}$ La discusión ética y ontológica es muy intensa sobre ello, y podríamos encuadrar las tendencias en aquellas que conceden al embrión el estatus de persona desde el momento de la fecundación, las que tienen una visión utilitarista o naturalista, que observan una condición no más importante que cualquier otra célula, y la mayoritaria, incluso entre las religiones (salvo la Católica), que mantienen la mencionada concepción gradual del embrión. Puede consultarse ABELLÁN, F., «Aspectos Bioéticos y legales del Diagnóstico Genético Preimplantacional (DGP)», Revista Iberoamericana de Fertilidad, 2006, vol. 3, n 2, pp. 126-128.

${ }^{7}$ A fecha de 21 de octubre de 2019 ha sido ratificado por Albania, Bosnia y Herzegovina, Bulgaria, Chipre, Croacia, Dinamarca, Eslovaquia, Eslovenia, España, Estonia, Macedonia, Finlandia, Francia, Georgia, Grecia, Islandia, Letonia, Lituania, Moldavia, Montenegro, Noruega, Portugal, República Checa, San Marino, Serbia, Suiza, Turquía y Hungría.
}

Solo lo firmaron Holanda, Italia, Luxemburgo, Polonia, Suecia y Ucrania. Ni han firmado ni han ratificado Alemania, Andorra, Armenia, Austria, Azerbaiyán, Bélgica, Irlanda, Liechtenstein, Malta, Mónaco, Reino Unido y Rusia.

El listado de países que han firmado o ratificado el Convenio, las fechas de incorporación a éste y las reservas particulares de cada Estado pueden consultarse en Chart of signatures and ratifications of Treaty 164, en la página web del Consejo de Europa: http://www.coe.int/en/web/conventions/full-list//conventions/treaty/164/signatures?p_auth=HBEXKUi8 (consultado 18/11/2019).

${ }^{8}$ ANDORNO, R., «The Oviedo Convention: A European Legal Framework at the Intersection of Human Rights and Health Law», Journal of International Business and Law, 2005, vol. 2, n. ${ }^{\circ}$ 4, p 134. Respecto al caso alemán, WEWETZER, H., «Alemania: sombras del pasado», The UNESCO courier, 1999, vol. 52, n. . 9, p 30, y asociaciones como el Centro de Referencia Alemana para la Ética en las Ciencias de la Vida (Deutsches Referenzzentrum für Ethik in den Biowissenschaften, DRZE), en la página web del DRZE: http://www.drze.de/imblickpunkt/organtransplantation/module/uebereinkommen-ueber-menschenrechte-und-biomedizin?set_language=de. La InteressenGemeinschaft kritische bioethik Deutschland (Comunidad de interés sobre Bioética crítica de Alemania), consideró que el Convenio de Oviedo permite un supuesto, esto es, la investigación de la línea germinal, que no está autorizado por la normativa alemana. También critica que autorice la experimentación, aun en ciertas circunstancias, en personas que no tienen capacidad de prestar su consentimiento (art. 17.2 CDHB), como recién nacidos, niños, personas con discapacidad mental, demencia senil o pacientes en coma, así como la extracción de tejidos sin el consentimiento de la persona donante, como en el caso de un hermano histocompatible con un tercero. Además reprocha que el Informe Explicativo del CDHB, en su nota 124, deje abierta la posibilidad a la donación de otros tejidos. En Informations-und Protestseite zur Biomedizin-Konvention (Bioethik-Konvention) des Europarates, en la página web de la InteressenGemeinschaft kritische bioethik Deutschland: http://www.bioethik-konvention.de/ (consultado 18/11/2019).

9 Aunque, según esta comisión, el Convenio de Oviedo prohíbe expresamente en su artículo 13. En Bioethikkommissionbeim Bundeskanzleramt, Präimplantationsdiagnostik (PID), 2004, p. 38. 
Adicional que analizaremos a continuación, como Australia, Canadá, Estados Unidos, Japón y México, así como la Santa Sede, y organizaciones la Unión Europea como organismo internacional. Ninguno de ellos lo firmó o ratificó ${ }^{10}$.

Esta singularidad tiene más importancia de la que parece, porque los factores históricos, las tradiciones, el contexto socioeconómico y religioso influyen sobremanera en el espíritu de las leyes locales, en su inexistencia y en qué medida las técnicas de reproducción humana asistida (TRHA) y la intervención de la línea germinal son llevadas a la práctica. A pesar de ello se trata de un convenio de amplio consenso, que posiblemente sea necesario revisar, dados los avances de la biotecnología genética humana.

Efectivamente, el convenio no hace mención expresa a las técnicas de reproducción humana asistida ni, obviamente, a los actuales métodos de selección de embriones. Conviene apuntar que en el momento de la aprobación del convenio apenas se habían desarrollado las múltiples aplicaciones del test genético preimplantacional, iniciadas en 1990, y que aún no existían las nuevas técnicas de prevención de enfermedades genéticas graves mitocondriales, o la edición del genoma mediante CRISPR-Cas9.

Esto hace que, tras una mirada retrospectiva y en el contexto actual, se observe cierta indefinición en los términos expresados el CDHB respecto a estas técnicas. La escasa concreción de los criterios del Capítulo IV, dedicado al genoma humano, dificulta la aplicación de ellas, por las dudas legales que se plantean, haciendo así su práctica imposible o dificultosa.

Por otro lado, la perspectiva actual de la intervención del genoma humano se encuentra más definida. Previo a la aprobación del convenio existía importante precaución acerca de la modificación del patrimonio genético humano, lógica por otra parte, pero que llevada al extremo suponía eliminar de manera consciente una línea de trabajo que permitía beneficios a nivel de salud para el ser humano, como prevenir una enfermedad genética grave mediante la eliminación directa del gen causante, o bien una mejora genética saludable. Sirva el artículo 1 de la Declaración Universal sobre el Genoma y Derechos Humanos, de 11 de noviembre de 1997 como ejemplo, el cual establece en sentido simbólico que el genoma humano es patrimonio de la humanidad ${ }^{11}$. Sin duda es un bien a proteger, pero también debemos pensar que una de las características de la condición humana es emplear todo su conocimiento para mejorar su calidad de vida, utilizando los recursos de los que dispone, y no cabe pensar que dejará de hacerlo en el campo de la biotecnología genética humana. La pregunta no es si se pueden hacer estas técnicas, sino con qué fin vamos a realizarlas. Nos toca formar parte de ese hecho, con el máximo respeto hacia nuestra especie ${ }^{12}$.

Sin olvidar que la perspectiva del Convenio de Oviedo debe ser generalista respecto a la intervención de la línea germinal, actualmente son varias las técnicas afectadas por esta ley, y que serían causa de posible modificación de sus criterios.

\footnotetext{
${ }^{10}$ Respecto a ello puede consultarse la referencia online expuesta en la nota 4.

${ }^{11}$ ROMEO CASABONA, C.M., «El Bioderecho y la Bioética, un largo camino en común», cit., pp. 14-15. Para el autor, la idea fue realizada con demasiada rapidez, antes de haberla profundizado, no solo por su alcance sino también por la adecuación de la afirmación, ya que podría abocar a la sacralización del patrimonio genético, sin posibles excepciones a su intervención, lo cual podría considerarse excesivo.

12 Como dice CAMPS, V., «¿Qué hay de malo en la eugenesia?», Isegoría: Revista de filosofía moral y política, $2002, \mathrm{n}^{\circ} 27$, p. 70 , «la condición humana es maleable y transformable, pero no debe ser transformada en su contrario que sería lo inhumano», o JONAS, H., Técnica, Medicina y Ética, Barcelona, Paidós, 1997, pp. 41-54, «obra de tal modo que los efectos de tu acción sean compatibles con la permanencia de una vida humana auténtica en la tierra». El mismo concepto es también expresado como: «no pongas en peligro las condiciones de la continuidad indefinida de la humanidad en la Tierra». O de esta manera: «incluye en tu elección presente, como objeto también de tu querer, la futura integridad del hombre».
} 


\section{TÉCNICAS DE INTERVENCIÓN GENÉTICA HUMANA ASOCIADAS AL CAPÍTULO IV DEL CDHB}

\section{II.1 Test genético preimplantacional}

El test genético preimplantacional es un método que consiste en la implantación en el útero de embriones tras el estudio de su material genético. Este puede realizarse antes de la fecundación, mediante el análisis de los corpúsculos polares femeninos, producidos en el proceso necesario para crear el óvulo, o después, observando el ADN de una o dos células del embrión, llamadas también blastómeras, en su tercer día de su desarrollo, o el del ADN obtenido cuando el embrión se encuentra en fase de blastocisto, al quinto o sexto día ${ }^{13}$.

El uso de una u otra técnica depende de circunstancias biológicas, éticas e incluso jurídicas, ya que el análisis de los corpúsculos polares femeninos solo implica la selección de los gametos femeninos que serán fecundados. Y, aunque es incompleta al no disponer de información respecto al gameto masculino, no involucra la selección de embriones, que está sujeta a un amplio debate ético en el que el principal factor es el estatus moral que se le confiere al embrión como persona. Otro inconveniente de la técnica es la creación de embriones sobrantes que no serán implantados, más cuando se realiza para obtener embriones histocompatibles con un hermano nacido y que padece una enfermedad que es posible ser tratada con éxito únicamente tras donación de su tejido hematopoyético.

La técnica fue empleada por primera vez en $1990^{14}$ y, aparte de la aplicación referida, se usó inicialmente para seleccionar embriones libres de padecer una enfermedad genética grave. En España está regulada por el artículo 12 de la Ley 14/2006, de 26 de mayo, sobre técnicas de reproducción humana asistida (LTRHA), que establece criterios amplios de uso. A nivel internacional es aceptada para fines médicos, y se rechaza para otros motivos, como la selección de sexo por causa no médica ${ }^{15}$ o la selección de embriones con alteraciones genéticas que predisponen a discapacidad. No obstante es una técnica que, salvo en Europa, está escasamente regulada, por lo que se producen consecuencias negativas derivadas de su uso, como desequilibrios demográficos en favor del sexo masculino, desigualdad social y económica en el

\footnotetext{
${ }^{13}$ Aunque la Sociedad Española de Fertilidad (SEF) aconseja analizar la blastómera en el tercer día de desarrollo, en MATORRAS, R., HERNÁNDEZ, J. (eds.): Estudio y tratamiento de la pareja estéril: Recomendaciones de la Sociedad Española de Fertilidad, con la colaboración de la Asociación Española para el Estudio de la Biología de la Reproducción, de la Asociación Española de Andrología y de la Sociedad Española de Contracepción. Adalia, Madrid, 2007, p. 335, estudios recientes demuestran mayor efectividad cuando se realiza sobre el blastocisto. En esta fase se describen varias partes: la masa celular interna, que es la que propiamente dará lugar al ser humano, el blastocele, que es una cavidad de líquido dentro del embrión, y el ectodermo o trofoectodermo, que es la parte que se unirá al útero y de donde se extraen las células que serán analizadas. Puede consultarse SCOTT, R.T., et al., «Cleavage-stage biopsy significantly impairs human embryonic implantation potential while blastocyst biopsy does not: a randomized and paired clinical trial». Fertility and Sterility, 2013, vol. 100, n 3, p. 630.

${ }^{14}$ HANDYSIDE, A.H., et al., «Pregnancies from biopsied human preimplantation embryos sexed by Y-specific DNA amplification», Nature. 1990; 344:768-770. Posteriormente informó del primer nacimiento de un hijo libre de fibrosis quística, en HANDYSIDE, A.H., et al., "Birth of a normal girl after in vitro fertilization and preimplantation diagnosis testing for cysting fibrosis», The New England Journal of Medicine, 1992, vol. 327, n. ${ }^{\circ} 13$, pp 905-909. El primer caso en España se produjo en 1994, en el Instituto Dexeus de Barcelona, en VEIGA, A., et al., «Case report: Twin pregnancy after preimplantation diagnosis for sex selection», Human Reproduction, 1994, vol. 9, $\mathrm{n}^{\circ}$ 11, pp. 2156-2159.

${ }^{15}$ Salvo en Israel, según la Directriz 2/12, de 25 de abril, sobre la autorización de la selección de sexo por causas no médicas, aceptándose por motivos emocionales, como equilibrio familiar, deseo incumplido, salud mental, amenaza del estatus social de los padres, o incluso religiosos.
} 
acceso a la prueba, la socialización de la selección de características discapacitantes, o el mal llamado "turismo reproductivo" o cross border reproductive care (CBRC). Por todo ello el TGP, antes denominado "diagnóstico genético preimplantacional", es causa de un intenso debate que perdura en el tiempo.

\section{II.2 Donación o reemplazo mitocondrial}

El objetivo de esta técnica es evitar enfermedades genéticas de carácter grave localizadas en el ADN de la mitocondria, localizado en este esencial orgánulo aunque en muy escasa cantidad ${ }^{17}$. En lugar de descartar el embrión con el gen mutado mediante TGP, se puede obtener uno sano por la participación de otro embrión o gameto femenino libre de enfermedad ${ }^{18}$.

Así, la donación mitocondrial puede realizarse mediante maternal spindle transfer (MST, o transferencia materna del uso) consistente en la extracción del huso mitótico del cigoto, o futuro núcleo. Posteriormente es introducido en otro cigoto donante, sin alteraciones genéticas mitocondriales, al cual se le ha extraído su propio huso mitótico. Este nuevo embrión sería el implantado.

La segunda técnica de donación mitocondrial es la transferencia pronuclear (pronuclear transfer, PNT), donde no se emplea el embrión, sino el gameto femenino, al cual se extrae su pronúcleo. A continuación se introduce en un gameto femenino donante, sin alteración genética mitocondrial y previa extracción de su propio pronúcleo. Este nuevo gameto será fecundado por el gameto masculino correspondiente.

En ambos casos se recurre a la participación de un tercer ADN, proveniente de un embrión (en el caso del MST) o un gameto femenino (en el PNT), por lo que en algunos medios audiovisuales se le ha denominado «técnica de tres padres genéticos». Esta afirmación parece carente de rigor científico, ya que el gameto o embrión resultante realmente posee menos de un $0.2 \%$ de material genético del tercero (37 genes, de un global de 20.000-25.000) ${ }^{19}$.

\footnotetext{
${ }^{16}$ En 2017 las principales sociedades científicas acordaron el cambio de denominación, ya que se consideraba que el término se prestaba a confusión. Efectivamente, en el concepto se incluía el screening preimplantacional, o test genético de detección de aneuploidías, cuya técnica y fin es la detección de enfermedades genéticas que provocan la inviabilidad del embrión, principalmente en mujeres de edad avanzada o con abortos de repetición, método que se diferencia del "diagnóstico preimplantacional" en sí, que consiste en la detección de predisposición de enfermedades genéticas monogénicas o derivadas de alguna alteración estructural cromosómica. Hoy día éstas últimas se les denomina TGP-M (o PGT-M en inglés) y TGP-AE (PGT-SR), respectivamente, mientras que el screening preimplantacional es llamado TGP-A (PGT-A). En ZEGERS-HOSCHSCHILD, G.D., et al., «The International Glossary on Infertility and Fertility Care, 2017», Fertility and Sterility, 2017, vol. 108, n 3, p. 404.

${ }^{17}$ En éste puede haber alteraciones genéticas que pueden ocasionar patologías como la enfermedad de Leigh, que en un 30-40\% de casos tiene su origen en una alteración génica del ADN mitocondrial. En THORBURN, D.R., RAHMAN, J., RAHMAN, S., Mitochondrial DNA-Associated Leigh Syndrome and NARP, (30 de octubre de 2003, última actualización 28 de septiembre de 2017. En página web de la revista digital GeneReviews: https://www.ncbi.nlm.nih.gov/books/NBK1173/ (consultado 18/11/2019). Actualmente la Enfermedad de Leigh está incluida en el listado de enfermedades susceptibles de TGP de la Human fertilisation and Embryology Authority (HFEA) del Reino Unido.

${ }^{18}$ El primer caso de donación o reemplazo mitocondrial en humanos fue realizado en Guadalajara (México),en la New Hope Fertility Center por el equipo científico dirigido por el Dr. Zhang, publicado en octubre de 2016 en ZHANG, J., et al., «First live birth using human oocytes reconstituted by spindle nuclear transfer for mitocondrial DNA mutation causing Leigh Syndrome», Fertility and Sterility, 2016, vol. 106, n 3, supl., pp. 375-376, con motivo del 72. ${ }^{\circ}$ Congreso Científico de la Sociedad Americana de Reproducción Médica (American Society for Reproductive Medicine, ASRM).

${ }^{19}$ Se puede consultar SALAS, J., Nace un bebé con la nueva técnica de 'tres padres genéticos' (artículo de prensa digital 6 de octubre de 2016), en la página web de El País: https://elpais.com/elpais/2016/09/27/ciencia/1474989059 678680.html (consultado 18/11/2019), y Así se crean los
} 
La carga ética de la prueba es menor cuando se recurre al PNT que al MST, ya que en la primera se recurre a gametos, los cuales no tienen una entidad que pudiera provocar el debate que genera el embrión en torno a su estatus moral como persona ${ }^{20}$. No obstante, debe advertirse que para la aplicación de la técnica es necesaria una fecundación in vitro previa.

La técnica es legal en Reino Unido que, recordemos, no ha firmado ni ratificado el Convenio de Oviedo $^{21}$. En España no se ha establecido norma alguna para su regulación ni parece encontrarse criterios que pudieran regularla en la Ley 14/2006, de 26 de mayo, sobre técnicas de reproducción humana asistida (LTRHA).

\section{II.3 Técnicas de edición del genoma}

El CRISPR-Cas9 es un sistema de defensa que poseen algunas bacterias que tiene la facultad de reconocer virus invasores, trocearlos y utilizar esos fragmentos para inmunizarse frente a ellos ${ }^{22}$. Este mecanismo biológico, descubierto por el profesor Francisco Mojica, pronto se observó que podría ser útil para editar el genoma humano, para introducir mutaciones en sitios concretos y crear así modelos celulares que permitan estudiar los mecanismos implicados en la aparición de las enfermedades oncológicas ${ }^{23}$, o bien para modificar la secuencia de ADN en la línea germinal, lo cual supone una revolución biotecnológica.

Actualmente las sociedades científicas involucradas en la técnica recomiendan autorizarla exclusivamente para ensayos clínicos con fines terapéuticos o prevención de enfermedades o discapacidades con implicación genética, y fomentar la discusión pública y

bebés con ADN de tres personas que Reino Unido busca legalizar (artículo de prensa digital, 3 de febrero de 2015), en la página web de la BBC: https://www.bbc.com/mundo/noticias/2015/02/150203_salud_tres_padres_votacion_il (consultado 18/11/2019).

${ }^{20}$ De hecho, en el primer caso de donación mitocondrial se recurrió a la trasferencia pronuclear, evitando utilizar embriones, debido a las convicciones religiosas de los progenitores (jordano musulmanes).

${ }^{21}$ El Reglamento por el cual se autoriza bajo ciertas condiciones la donación mitocondrial fue publicado en 29 de octubre de 2015 (Human Fertilisation and Embryology (Mitochondrial Donation) Regulations 2015), aceptándose en sus dos variedades siempre que exista un riesgo particular de que el óvulo o gameto de la persona o pareja solicitante pueda tener una anormalidad en el ADN mitocondrial y pueda desarrollarse una enfermedad genética grave. La solicitud debe ser autorizada por el Comité de Licencias de la HFEA (Human Fertilisation and Embryology Authority), y la primera que fue aceptada fue publicada el 15 de marzo de 2017. Puede consultarse en HFEA statement on mitochondrial donation, en la página web de la HFEA: https://www.hfea.gov.uk/about-us/news-andpress-releases/2017-news-and-press-releases/hfea-statement-on-mitochondrial-donation/ (consultado 18/11/2019).

${ }^{22}$ Concretamente, el CRISPR es una cadena de secuencias repetidas de ADN que se encuentra en el genoma de la bacteria, separadas entre sí por secuencias espaciadoras de unos 36 genes. De ahí la denominación, «clustered regularly interspaced short palindromic repeats »(CRISPR), esto es, «repeticiones palindrómicas breves, agrupadas y espaciadas de forma regular». Éstas se acompañan de un grupo de genes que se les denominó Cas (de la inicial CRISPR-associated). La información genética que contienen es capaz de transcribirse y procesarse en una molécula de ácido ribonucleico (ARN), que se acompaña de la proteína Cas. Por este sistema, cuando la bacteria es infectada por un virus, o fago, tiene la facultad de reconocer su ADN, ya que la secuencia CRISPR de la bacteria es el recuerdo genético heredado de una infección producida en una bacteria antecesora. Así, la molécula CRISPR-Cas se unirá al ADN del fago por complementariedad, y esto será el detonante para que la proteína Cas corte el ADN del fago con absoluta precisión, provocando su inactivación. Posteriormente puede unir esos fragmentos y editarlos, en beneficio de la bacteria. Para más información, puede consultarse National Academics of Sciences, Engineering and Medicine. Human Genome Editing. Science, ethics and governance, The National Academies Press, Washington DC, 2017, pp 218-224, y TORRES, S. «Desafíos éticos y jurídicos de las nuevas tecnologías genómicas "reescribir el genoma: un sueño al alcance de la mano"», en la página web Studylib: https://studylib.es/doc/7747586/desaf\%C3\%ADos\%C3\%A9ticos-y-jur\%C3\%ADdicos-de-las-nuevas-tecnolog\%C3\%ADas (consultado 19/11/2019).

${ }^{23}$ Como el sistema generado en el Centro Nacional de Investigaciones Oncológicas para generar un modelo celular de sarcoma de Ewing, en TORRES-RUIZ, R., «Efficient Recreation of t(11;22) EWSR1-FLI1+ in Human Stem Cells Using CRISPR/Cas9», Stem Cell Reports, 2017, vol. 8, nº 5, pp. 1408-1420. 
política sobre su aplicación para fines distintos a éstos ${ }^{24}$. La precaución es lógica, ya que en el método todavía se aprecian importantes problemas técnicos, como la creación de mutaciones y mosaicismos, e implica dilemas éticos severos ${ }^{25}$.

Ello no fue obstáculo para que el 25 de noviembre de 2018 el equipo de He Jiankui, de la Universidad de la SUSTech (China), anunciara el nacimiento con éxito de dos gemelas en el que se había desactivado el gen CCR5 mediante CRISPR-Cas9 y, por tanto, inmunes a la infección por $\mathrm{VIH}^{26}$. Esta comunicación fue filtrada a la prensa ${ }^{27}$, y presentada días más tarde en la Segunda Cumbre Internacional de Edición del Genoma Humano, celebrada en Hong Kong, donde se criticó la irresponsabilidad del equipo que realizó la prueba, así como los errores de diseño, la falta de supervisión y transparencia, y el haberla aplicado para prevenir una enfermedad que actualmente tiene tratamiento válido ${ }^{28}$. Hasta hoy su trabajo no ha sido publicado en revista científica, y su materialización ha sido condenada de forma unánime, calificándose el experimento como un «desastre ético imprudente» ${ }^{29}$. A raíz del caso, el Comité de Bioética de España (CBE), emitió un informe en 2019 en el que destaca las deficiencias técnicas de la prueba, manifestando su rechazo al uso de la técnica para fines directos o indirectos de mejora genética y llamando al respeto de la dignidad e igualdad de todos los seres humanos para el uso de ésta ${ }^{30}$.

No obstante, la prudente tendencia actual no es contraria en absoluto a la aplicación de la técnica, que podría ser de gran utilidad para el tratamiento de determinadas enfermedades genéticas, y algunos organismos, como la Sociedad Europea de Reproducción y Embriología Humana (ESHRE) y la Sociedad Europea de Genética Humana (ESHG), han declarado su

\footnotetext{
${ }^{24}$ The National Academics of Sciences, Engineering and Medicine. Human Genome Editing. Science, ethics and governance, cit., p. 159.

${ }^{25}$ LANPHIER, E., et al., «Don't edit the human germ line», Nature, 2015, vol. 519, $\mathrm{n}^{\text {o }} 7544$, pp. 410-411, y BALTIMORE, D., et al., «A prudent path forward for genomic engineering and germline gene modification», Science, 2015 , vol. 348, n. $^{\circ} 6230$, p. 38, reclaman una moratoria voluntaria en la comunidad científica que desalienten la intervención de la línea germinal humana y aumentara la conciencia pública sobre la diferencia entre la actuación sobre la línea germinal y las células somáticas. Así mismo, la Chinese Academy of Sciences, la Royal Society de Reino Unido, la National Academy of Sciences y la National Academy of Medicine de Estados Unidos, recomendaron limitar la intervención en la línea germinal a la investigación mientras que no sean debatidas sus implicaciones éticas, jurídicas y sociales por parte de las organizaciones científicas y gubernamentales, en International Summit on human gene editing, On Human Gene Editing: International Summit Statement, 1-3 de diciembre de 2015, en la página web de The National Academies of Sciences Engineering Medicine: http://www8.nationalacademies.org/onpinews/newsitem.aspx?RecordID=12032015a (consultado 19/11/2019).

${ }^{26}$ En 2015 se realizó el primer intento de modificar el genoma en un embrión humano. La investigación fue realizada en la Universidad de Sun Yat-sen, de Guangzhou, y demostró la capacidad del CRISPR-Cas9 para escindir el gen endógeno de la ß-globina (HBB) del cromosoma 11 embrionario, aunque concluyó que debía mejorarse la técnica. En LIANG, P., XU, Y., ZHANG, X., et al., «CRISPR/Cas9-mediated gene editing in human tripronuclear zygotes», Protein Cell, 2015, vol. 6, n 5, pp. 363-372.

${ }^{27}$ VIDAL LIY, M. Científicos chinos aseguran haber creado los primeros bebés modificados genéticamente (artículo de prensa digital, 26 de noviembre de 2018) en la página web de El País: https://elpais.com/elpais/2018/11/26/ciencia/1543224768_174686.html (consultado 19/11/2019).

${ }^{28}$ Second International Summit on Human Genome Editing: Continuing the Global Discussion. Proceedings of a Workshop - in Brief, pp 2-3, en la página web de The National Academies of Sciences, Engineering and Medicine : https://www.nap.edu/download/25343\# (consultado 19/11/2019). Posteriormente, el científico fue condenado a tres años de prisión, en SANTIRSO, J., Condenado a tres años de cárcel el científico chino que creó los primeros bebés modificados genéticamente (artículo de prensa digital, 30 de diciembre de 2019), en la página web de El País: https://elpais.com/elpais/2019/12/30/ciencia/1577710962 002091.html (consultado 19/11/2019).

${ }^{29}$ GREELY, H.T., «CRISPR'd babies: human germline genome editing in the 'He Jiankui affair'», Journal of Law and the Biosciences, 2019, vol. $6 \mathrm{n}^{\circ} 1, \mathrm{p} .113$.

${ }^{30}$ Comité de Bioética de España, Declaración del Comité de Bioética de España sobre la edición genómica en humanos, 16 de enero de 2019.
} 
aprobación para mejoras genéticas que podrían ser valoradas ${ }^{31}$.

La edición del genoma no está regulada en ningún país, aunque en Reino Unido la Ley de Fertilización y Embriología (Human Fertilisation and Embryology Act) ofrece un modelo flexible y permisivo hacia su uso para la investigación (apartado $3^{a} .2$ de su Anexo 2). De hecho el Comité de Licencias de la HFEA aprobó una solicitud en febrero de 2016 del Instituto Francis Crick por el que se autorizó una licencia de investigación para aplicar técnicas de edición del genoma en embriones ${ }^{32}$. En España, la Comisión Nacional de Reproducción Humana Asistida (CNRHA), aprobó en febrero de 2020 el uso de la técnica CRISPR-Cas9 para suprimir genes y estudiar su función en el desarrollo embrionario ${ }^{33}$.

\section{II.4 Otras técnicas}

En octubre de 2018, un equipo de investigación japonés logró crear gametos humanos a partir de células sanguíneas, mediante una nueva técnica denominada gametogénesis in vitro ${ }^{34}$. Aunque el artículo publicado en Science expone que todavía no se ha logrado obtener un óvulo maduro, necesario para proceder a una fecundación in vitro, sí que se consiguió en experimentación animal. Parece un tanto sensacionalista concluir que el ser humano podría reproducirse sin necesidad de dos personas de sexo opuesto, pero abre la posibilidad a la gestación autónoma de madres solteras, a problemas de infertilidad masculina y femenina o a la necesidad de recurrir a la donación de óvulos o esperma por parte de terceras personas.

Otra técnica, denominada en inglés Preimplantation genetic haplotyping (PGH), es realmente una variedad del test genético preimplantacional, consistente en la selección de embriones tras un análisis genético de familiares afectados y no afectados de una enfermedad monogénica ${ }^{35}$.

\footnotetext{
${ }^{31}$ La Sociedad Europea de Reproducción y Embriología Humana (ESHRE) y la Sociedad Europea de Genética Humana (ESHG), mostraron su preocupación derivada de la técnica, debida a los cambios genéticos heredables a generaciones futuras, aunque consideran dignas de evaluar mejoras en algunos fines médicos como el fortalecimiento del sistema inmune, la edición de embriones con condiciones recesivas, o las relacionadas con coeficiente intelectual. En DE WERT, G., HEINDRYCKX, B., et al., «Responsible innovation in human germline gene editing: Background document to the recommendations of ESHG and ESHRE», European Journal of Human Genetics, 2018, vol. 6, n 4, p. 464.

${ }^{32}$ FOGARTY, N.M.E., et al., «Genome editing reveals a role for OCT4 in human embryogenesis», Nature, 2017, vol. $550, \mathrm{n}^{\circ} 7674$, pp. 67-73.

${ }^{33}$ ANSEDE, M., Autorizada la modificación de los genes de 40 embriones humanos en España (artículo de prensa digital, 10 de febrero de 2020), en la página web El País: https://elpais.com/elpais/2020/02/10/ciencia/1581359329_317929.html (consultado 19/11/2019).

${ }^{34}$ YAMASHIRO, C., et al., «Generation of human oogonia from induced pluripotent stem cells in vitro», Science, 2018, vol. 362, n. ${ }^{\circ}$ 6412, p 360. También puede consultarse MARINERO, I., El fin del sexo reproductivo: llega la técnica que permitirá tener hijos sin la intervención del varón (artículo de prensa digital, 7 de diciembre de 2018), en la página web de El Mundo: https://www.elmundo.es/papel/historias/2018/12/07/5c095a18fdddff4f568b46fb.html (consultado 20/11/2019).

${ }^{35}$ Así, esta técnica es capaz de crear un mapa de haplotipos en el árbol genealógico familiar, que ayuda a identificar las secuencias o haplotipos de alto riesgo (o sea, los portadores de mutaciones) y los de bajo riesgo. Una vez que se conocen, se pueden seleccionar los embriones que serán transferidos al útero, eligiendo aquellos que tengan el ya conocido haplotipo de bajo riesgo. Esta prueba permite la identificación de la mutación genética específica que produce la enfermedad o incluso la variable grave dentro de ésta. Para más información puede consultarse RENWICK, P.J., et al., «Proof of principle and first cases using preimplantation genetic haplotyping-a paradigm shift for embryo diagnosis», Reproductive BioMedicine Online, 2006, vol. 13, nº 1, pp. 110-119.
} 


\section{DISCUSIÓN RESPECTO AL CAPÍTULO IV DEL CDHB}

Como hemos adelantado, el Capítulo IV CDHB es el que establece los criterios relacionados con el genoma humano. De todos ellos los que sin duda despiertan más dudas razonables son los incluidos en el artículo 13, por otro lado esenciales para determinar o no la legalidad de las nuevas técnicas de intervención del genoma. Además, el Informe Explicativo del Convenio de Oviedo, que fuera elaborado bajo responsabilidad del Consejo de Europa, tampoco consigue aclarar cuáles son los límites de aplicación, no solo por el evidente decalaje temporal, sino también porque no deja vislumbrar en su interpretación algunas líneas argumentales que serían decisivas ${ }^{36}$.

\section{III.1 Artículo 11 CDHB}

Este artículo prohíbe toda discriminación de la persona por causa de su patrimonio genético. De acuerdo con el apartado 76 del Informe Explicativo, el CDHB añade al deber de garantizar los derechos y libertades establecidos en el Convenio Europeo sobre Derechos Humanos la no discriminación por la herencia genética de una persona, con lo que podemos confirmar que el CDHB incorpora nuevos derechos al marco jurídico establecido previamente.

\section{III.2 Artículo $12 \mathrm{CDHB}$}

El artículo dispone que sólo podrán realizarse pruebas genéticas de tipo predictivo de enfermedad genética, la identificación del portador de un gen responsable de una enfermedad, o la detección a una predisposición o susceptibilidad genética a ella, mientras que sean con fines médicos o de investigación médica y con un asesoramiento genético adecuado.

Aclara el Informe Explicativo en su apartado 83 que el artículo 12 no pone limitación a realizar intervenciones diagnósticas en fase embrionaria para detectar características hereditarias que puedan producir riesgo de transmisión de enfermedad grave. Esto descartaría que el test genético preimplantacional esté prohibido por el CDHB, al menos respecto a la predicción o predisposición a padecer una enfermedad genética grave, aunque podría haber alguna contradicción con el artículo 13, como observaremos más adelante. También expone en los apartados 84 y 86 que las pruebas genéticas predictivas quedan excluidas para fines privados, como contratos de seguro o de trabajo, aunque podrían aceptarse si estuvieran orientadas a la salud de las personas.

Es importante apuntar que los conceptos predicción, predisposición y portador no significan lo mismo. La predicción de enfermedad se confirma al encontrar el gen mutado responsable; éste puede tener una penetrancia completa (es decir, el poseerlo significa el padecimiento seguro de la enfermedad) o incompleta (o sea, una predisposición a enfermedad, como ocurre por ejemplo en el cáncer hereditario de mama al poseer los genes BRCA1 o BRCA2, que se traduce en una probabilidad de padecer el tumor, no la certeza ${ }^{37}$. Por último, ser portador de un gen mutado no conlleva necesariamente la enfermedad. El ejemplo más

\footnotetext{
${ }^{36} \mathrm{El}$ Informe Explicativo del Convenio para la protección de los derechos humanos y la dignidad del ser humano con respecto a las aplicaciones de la Biología y la Medicina, de 4 de abril de 1997, aun no siendo una interpretación autorizada del convenio, tuvo como objetivo proporcionar información acerca de éste para e sus disposiciones.

${ }^{37}$ Para más información se puede consultar NUSSBAUM, R.L., McINNES, R.R., WILARD, H. F., Thompson \& Thompson Genetics in medicine, 7. . Ed., Saunders, Philadelphia, 2007, p. 119.
} 
evidente se encuentra en enfermedades genéticas ligadas a sexo, en las que los varones padecen la enfermedad y las mujeres son portadoras ${ }^{38}$.

\section{III.3 Artículo 13 CDHB}

Este controvertido artículo determina las intervenciones sobre el genoma humano y, como tal, merece ser transcrito en su totalidad para el consiguiente análisis:

\section{«Intervenciones sobre el genoma humano. \\ Únicamente podrá efectuarse una intervención que tenga por objeto modificar el genoma humano por razones preventivas, diagnósticas o terapéuticas y sólo cuando no tenga por finalidad la introducción de una modificación en el genoma de la descendencia».}

Haciendo una lectura rápida, el artículo es contundente. No cierra por completo la posibilidad de intervenirlo, pero tiene un objetivo claro: la protección del embrión y el patrimonio genético humano. De hecho el apartado 89 del informe es manifiestamente claro cuando afirma que «mientras que los avances en este campo pueden proporcionar un gran beneficio a la humanidad, su empleo abusivo puede poner en peligro no sólo al individuo, sino a la especie en sí misma», y expresa el miedo a la modificación intencionada del genoma humano «para producir individuos o grupos» con ciertas características o cualidades seleccionadas. El problema es su excesiva protección, de tal forma que algunos autores entienden que el art. 13 CDHB impone una prohibición absoluta a la intervención de la línea germinal ${ }^{39}$, mientras que otros afirman que el convenio dejó conscientemente la posibilidad de intervenirla en determinadas situaciones ${ }^{40}$. En nuestra opinión la literalidad del art. $13 \mathrm{CDHB}$, por contradictorio que parezca, está sujeto a interpretaciones diametralmente opuestas, ya que obliga a estar de acuerdo en parte con ambas tesis. Parece necesaria su modificación, más con la aparición de las nuevas técnicas de intervención del genoma.

Partamos de una circunstancia que no parece tener duda, y es que el convenio autoriza la intervención del genoma en células somáticas, esto es, cualquiera que no pertenezca a tejido embrionario, como piel, músculo, tejido adiposo y otros, ya que ello no modifica el genoma de la descendencia y además va destinado al tratamiento, diagnóstico o prevención de una enfermedad del propio individuo, por ejemplo de tipo oncológico ${ }^{41}$.

\footnotetext{
${ }^{38}$ La única manera por la que puede expresarse una enfermedad genética es cuando el gen es de tipo dominante, porque basta con transmisión por un solo progenitor, o bien el recesivo si es transmitido por ambos progenitores. La única posibilidad de expresión de un gen recesivo transmitido por un solo progenitor ocurre en las enfermedades ligadas a sexo cuando el embrión es masculino (XY). Esto es porque el único cromosoma X que posee hace que el gen recesivo actúe como dominante. En este caso, los embriones femeninos solo son portadores de enfermedad, y no la padecerán.

${ }^{39}$ Como RAPOSO, V.L., «The convention of human rights and biomedicine revisited: Critical assessment», The International Journal of Human Rights, 2016, vol. 20 n..$^{\circ}$, p 129, ANDORNO, R., "The Oviedo Convention: A European Legal Framework at the Intersection of Human Rights and Health Law", cit., p. 140, o BELLVER CAPELlA, V., "Los Diez Primeros Años del Convenio Europeo sobre Derechos Humanos y Biomedicina: Reflexiones y Valoración”, Cuadernos de Bioética, 2008, vol. 19, n 3, p. 408.

${ }^{40}$ DE MIGUEL, I., LAZCOZ, G., «El Convenio de Oviedo, veinte años después de su firma. Algunas sugerencias de enmienda», cit., p. 450.

${ }^{41}$ De hecho, el apartado 92 del informe Explicativo manifiesta que« el artículo no prohíbe las intervenciones de tipo somático que podrían tener efectos secundarios no deseados en la línea germinal». La mejora genética del propio individuo es, generalmente más aceptada, como afirma LEMA, C., «iMejores que quién? Intervenciones de mejora, derechos humanos y discriminación», en Romeo Casabona (ed.): Más allá de la Salud: intervenciones de mejora en humanos, Bilbao-Granada, Comares, 2012, p. 53.
} 
A nuestro juicio, el artículo tiene esencialmente dos condicionantes.

\section{A) Modificación por razón de prevención, diagnóstico o tratamiento}

En el caso de la línea germinal, la actuación se realizaría sobre un gen mutado, presente en el ADN del embrión o en los gametos que darán lugar a la futura persona ${ }^{42}$.

Según expone el apartado 90 del informe, el art. 13 CDHB prohíbe las intervenciones dirigidas «a la modificación de características genéticas que no están asociadas a una enfermedad». Por sí solo, este primer condicionante del art. 13 CDHB no impide el uso de las nuevas técnicas de intervención del genoma, incluida la edición del genoma, aunque sí podría desautorizarlo el segundo, que veremos a continuación.

Pero más allá de la enfermedad, el Informe Explicativo no contempla otras posibilidades que recortan la calidad de vida y que actuando sobre el genoma podrían evitarse. Así, debemos incluir cualquier alteración genética que merme las capacidades físicas o psíquicas esperables en el ser humano como especie. Nos referimos a las discapacidades, discutido término que hoy día debe distinguirse del concepto de enfermedad, no solo en el plano físico y psíquico, sino también en el ámbito de las relaciones laborales.

Además, adentrándonos en un debate sobre límites de actuación, y ateniéndonos a las sabidas definiciones de la OMS o del Informe Hastings Center de Nueva York ${ }^{43}$, deberían aceptarse las mejoras genéticas relacionadas con la salud, una vez que se alcance un consenso multidisciplinar respecto a su uso, se garantice en las nuevas técnicas de intervención genética su seguridad y se predigan todas sus consecuencias. La mejora genética es el nuevo factor de discusión, y en un futuro arribarán nuevos retos. Por ello el debate de la mejora genética de la línea germinal debe ser cauto pero sin temor a afrontarlo. Por otro lado, si la modificación genética se realiza en condiciones de equidad, y afecta a una mejora irrenunciable de salud, ¿habría gran impedimento en realizarla? Volvemos a una idea previa. No es la especie, sino la condición humana la que se debe preservar. De acuerdo con la opinión de González Morán, previo a la aplicación de una mejora genética sería preciso definir cuál es el nivel de normalidad en salud ${ }^{44}$. Pero añadiría que ese nivel de normalidad debería concretarse en la mejora genética que se quiere intervenir, en armonía con el resto de mejoras posibles, y abandonando la idea de que ese nivel de normalidad en salud, como especie, es propio e inalterable. Nunca ha sido así, evidentemente. Los condicionantes sociales de salud y la medicina han contribuido a mejorar la calidad y esperanza de vida de las personas, y lo seguirán haciendo esta vez con la biotecnología genética como actor.

\section{B) Prohibición de la modificación del genoma de la descendencia}

Sin duda es el requisito que causa mayor incertidumbre y que, como hemos expuesto, está sujeto a interpretaciones contrapuestas de forma justificada.

Para comenzar el artículo 13 CDHB debería concretar, al referirse a la descendencia, si

\footnotetext{
${ }^{42}$ Entendiendo el tema que discutimos desde un concepto gradual del estatus moral del embrión.

${ }^{43}$ Salud es «la experiencia de bienestar e integridad del cuerpo y la mente. La salud se caracteriza por la ausencia de males de consideración y, por tanto, por la capacidad de una persona para perseguir sus metas vitales y desenvolverse adecuadamente en contextos sociales y laborales habituales», en Los fines de la medicina (traducción al español de The goals of medicine. Setting new priorities. Hastings Cent Rep, 1996, vol. 26, nº 6, supl., pp. S1-S27, $2^{\mathrm{a}}$ ed, Fundació Grifols y Lucá, Barcelona, 2007, p. 35.

44 GONZÁLEZ MORÁN, L., «Implicaciones éticas y jurídicas de las intervenciones de mejora en humanos. Reflexión general», en Romeo Casabona, C.M. (ed.): Más allá de la Salud: intervenciones de mejora en humanos, Comares, Bilbao-Granada 2012, p. 4.
} 
se refiere a la modificación genética del linaje general de los progenitores, o bien a la de un embrión en particular. Porque eso cambia el contexto del problema. Un test genético preimplantacional no modifica el ADN del embrión, pero sí el de la descendencia entendida como estirpe, ya que va a evitar la transmisión de una enfermedad genética grave a las siguientes generaciones. Entendido así, el art. 13 desautoriza el TGP. Como mantuvimos al analizar el art. $12 \mathrm{CDHB}$, esta prueba parece estar autorizada, pero existe una contradicción en el convenio que conviene analizar.

Por otro lado, el apartado 91 del Informe Explicativo desautoriza cualquier intervención que introduzca un cambio en el genoma de los descendientes, y pone como ejemplo específico «la modificación de espermatozoides u óvulos destinados a la fecundación». Bajo nuestro punto de vista, no deja claro si se alude también a las modificaciones no genéticas, como el enriquecimiento del semen a favor del sexo masculino o femenino, para conseguir un embrión con el sexo determinado ${ }^{45}$. Si el espíritu del convenio entiende que sin actuar directamente sobre el ADN de los gametos sexuales también se modifica el genoma de la descendencia, entonces por analogía el TGP debería estar prohibido. Por otro lado resulta curioso que el apartado 90 no aluda a las modificaciones en el embrión y, como comentamos anteriormente, hay autores que sospechan de una clara intencionalidad, para dejar abierta la puerta a su futura intervención ${ }^{46}$.

Por tanto, apreciamos una evidente incoherencia en este aspecto. Podría interpretarse incluso que el art. 13 CDHB se refiere a la no modificación de la descendencia de un embrión, si tras su desarrollo evolutivo deviene en una persona que tuviera prole.

Esta falta de concreción afecta también a la donación mitocondrial. Como expusimos anteriormente, las dos formas de ejecutar esta técnica crean un embrión modificado genéticamente de forma indirecta, ya que incorpora un nuevo ADN, el mitocondrial, donado por un tercero. Si seguimos la misma interpretación, esta técnica también estaría prohibida. El único país que ha legalizado su uso es Reino Unido, que no ha firmado ni ratificado el convenio, por lo que no existe actualmente sobre la cuestión una contradicción entre normas nacionales y supranacionales.

Lo que aparenta ser más clara es la prohibición de la modificación directa del genoma humano, y ello afecta a las técnicas de edición genética como el CRISPR-Cas9. Y hablamos de apariencia, porque ¿la finalidad de esta prueba, y las anteriores, es la introducción de una modificación en el genoma de la descendencia? Bajo nuestro criterio en absoluto. El empleo de estas técnicas en el campo de la salud no tiene ese objetivo, sino prevenir, diagnosticar o tratar la enfermedad que va a padecer el individuo, ya sea evitando la implantación de un embrión con un gen mutado, en el caso del TGP o la donación mitocondrial, o bien reemplazando e insertando un gen libre de mutación, en el caso de las técnicas de edición del genoma. Dicho de otra manera, la modificación del genoma de la descendencia es una consecuencia inevitable que tiene como fin la prevención o restauración de la salud del individuo que va a nacer ${ }^{47}$.

\footnotetext{
${ }^{45}$ Esta técnica evita el dilema ético de tener que seleccionar embriones. No obstante tiene una clara intencionalidad, ya que el fin último es seleccionar el sexo. Su fiabilidad es escasa, ya que es de un $90 \%$ para el sexo femenino y un $60 \%$ para el masculino, lo cual hace que las clínicas de reproducción asistida se decanten por el TGP. A favor del enriquecimiento del semen se encuentran autores como EGOZCUE, J., «Preimplantation Social Sexing: A Problem of Proportionality and Decision Making», Journal of Assisted Reproduction and Genetics, 2002, vol. 19, nº 9, p. 441, y el Observatorio de Bioética y Derecho, Documento sobre la selección de sexo, Barcelona, febrero de 2003.

${ }^{46}$ Ver nota 37.

${ }^{47}$ En ese sentido, DE MIGUEL, I., LAZCOZ, G., «El Convenio de Oviedo, veinte años después de su firma. Algunas sugerencias de enmienda», cit., p. 450, respecto a las técnicas de edición del genoma manifiestan que es un tanto exagerado que afirmar que sostener que el fin es modificar el genoma de la descendencia cuando se actúa en el embrión intervenido.
} 
En definitiva, la segunda condición que plantea el art. 13 CDHB parece confusa e incluso prescindible. Sí que es razonable atenerse a la primera condición, esto es, la autorización de estas técnicas únicamente cuando tengan por objeto modificar el genoma humano por razones preventivas, diagnósticas o terapéuticas, y considerar como ineludible la modificación del genoma de la descendencia no solo para alcanzar ese objetivo, sino también porque va en beneficio de la futura persona y su descendencia. Si lo que pretende el convenio es evitar el carácter eugenésico de las pruebas, la creación de élites genéticas o el uso con fines no médicos, creemos que la fórmula elegida no es la más correcta.

No es objeto del presente trabajo resolver completamente la cuestión, que sería objeto de un profundo análisis. Pero sí que debemos realizar dos puntualizaciones. En primer lugar, la naturaleza ha empleado la eugenesia para modificar y seleccionar especies, en el contexto de la evolución natural. El ser humano, evidentemente, no ha sido ajeno a estos cambios genéticos y epigenéticos, con los cuales ha ido adaptándose al medio. La misma naturaleza realiza una selección genética natural que se traduce en un $50-70 \%$ de abortos espontáneos o subclínicos ${ }^{48}$. No podemos equiparar el objetivo de estas técnicas a experiencias realizadas en el pasado por el ser humano, completamente execrables.

En segundo lugar, debemos ser conscientes de que el TGP ya realiza una mejora genética de las siguientes generaciones, al evitar la transmisión de enfermedades genéticas de carácter grave, pudiéndose comprobar actualmente la menor incidencia de patologías como el síndrome de Down o la espina bífida ${ }^{49}$, y ello no despierta mayor debate ético entre la comunidad científica, la normativa internacional e incluso la mayoría de las religiones. Por otro lado, cualquier mejora genética introducida mediante edición del genoma supone la creación de una persona con un nuevo patrón genético que se va a transmitir a las siguientes generaciones si se reproduce la persona que nazca del proceso ${ }^{50}$. Ello podría engendrar problemas todavía no resueltos, como la creación de grupos de individuos privilegiados, inmunes a determinadas enfermedades, con una mejor calidad de vida y una esperanza de vida mayor. Por tanto, ante la modificación del art. 13 conviene ser cautos y realizar previamente un debate sobre qué mejoras genéticas son admisibles, teniendo en cuenta factores de objetividad y universalidad, y tomando las medidas necesarias para evitar lo verdaderamente importante, esto es, que unas hipotéticas élites genéticas se conviertan en élites sociales.

En España la Ley 14/2006 tuvo la previsión de articular unos principios respecto a la aplicación de técnicas terapéuticas en el embrión. Si bien en el momento de publicación de la LTRHA no existían, actualmente el artículo 13 LTRHA podría corresponderse con las técnicas de edición del genoma, ya que debemos entender que tanto el TGP como la donación mitocondrial son de carácter preventivo, mientras que la edición del genoma puede emplearse con fines terapéuticos. En definitiva, podemos decir que la LTRHA fue novedosa en este aspecto y respecto a otras normas de carácter internacional. No obstante, la realización en nuestro país de estas técnicas a nivel terapéutico está impedida por la posible contradicción con el art. 13 CDHB, y por ser necesaria su regulación por real decreto, según dispone el apartado 13.2.d) LTRHA. Ello no ha impedido la aprobación de la técnica por parte de la CNRHA con fines de investigación.

\footnotetext{
${ }^{48}$ SADLER, T.W. Embriología médica de Langman, 12ª Edición (edición en español), Wolters Kluwer, Barcelona, 2013, p. 43.

${ }^{49}$ NOGUÉS. R.M., «Eugenesia en humanos: delicada e inevitable», », Bioética \& Debat, 2009, vol. 15, n 56, p. 9.

${ }^{50}$ Entendemos que no cabe caer en el optimismo tecnológico de diferentes autores como PIERCE, D., en $L a$ Revolución Reproductiva (2009), en la página web Hedweb: http://www.hedweb.com/reproductiverevolution/index.html (consultado 20/11/2019), respecto a la deriva hacia la reproducción de la especie humana mediante fecundación in vitro.
} 


\section{III.4 Artículo 14 CDHB}

Este artículo no admite la aplicación de las técnicas analizadas para seleccionar el sexo de la persona que va a nacer, salvo que fuera preciso para evitar una enfermedad genética grave ligada a sexo. Aunque el debate respecto a la selección de sexo por razones diferentes a las de salud, como las de equilibrio familiar, es intenso y tiene numerosas opiniones a su favor, tanto el Convenio de Oviedo como el Informe Explicativo son claros en este aspecto, impidiendo su realización salvo por motivos médicos. Es importante reiterar la posibilidad de ser portador de la enfermedad. De hecho, en el caso de enfermedades ligadas a sexo, se selecciona el sexo femenino ya que, aunque es portador de la enfermedad, no la va a padecer. El motivo de que se proceda a ello y no a localizar embriones de sexo masculino libres de enfermedad es porque el TGP, que es la técnica empleada, actualmente no es capaz de diferenciar éstos de los que portan el gen mutado.

Cabe reseñar que la edición del genoma haría innecesaria la selección de embriones por sexo, ya que el método actúa directamente sobre el embrión que contiene el gen mutado, sea masculino o femenino, eliminado la posibilidad de padecer la enfermedad independientemente del género. La posibilidad de seleccionar el sexo por razones no médicas es una posibilidad que actualmente debe rechazarse, mientras que persistan factores socioculturales y fenómenos migratorios que favorezcan la selección de sexo a favor del varón.

\section{CONCLUSIONES}

Hemos podido comprobar que el Convenio de Oviedo, habiendo supuesto un avance esencial a nivel jurídico de consenso en materia de derechos humanos y biomedicina, veintitrés años después necesita adecuarse al nuevo contexto social y científico respecto a las técnicas de intervención de la línea germinal humana. Ello no va en su detrimento, y es consecuencia lógica de los avances de la ciencia, que habitualmente se adelantan al proceso deliberativo de la ética y el derecho.

Actualmente hay técnicas sobradamente implantadas y aceptadas, como el test genético preimplantacional, que necesitan por parte del CDHB que sus sean menos confusos. Otras técnicas recientes, como la donación mitocondrial, que produce una modificación indirecta del genoma de las siguientes generaciones, se verían beneficiadas en el mismo sentido. Respeto a la edición del genoma, mientras que no se establezca un verdadero y audaz debate multidisciplinar respecto a su uso, no debería disponerse un criterio definitivo a nivel jurídico. A modo de sugerencia, si se permite la propuesta, sería aconsejable clarificar la condición final del artículo 13, esto es, la aceptación de la intervención del genoma humano «sólo cuando no tenga como fin la modificación del genoma de la descendencia», para limitar por el momento el uso de las técnicas de edición del genoma al campo de la investigación. Por tanto, la propuesta podría ir dirigida a autorizar la intervención sólo cuando no tenga como consecuencia la modificación directa del genoma de la descendencia, salvo para fines de investigación.

Como anteriormente expusimos, las nuevas técnicas de intervención del genoma pueden ser una herramienta útil y necesaria para el diagnóstico, prevención y tratamiento de las enfermedades y discapacidades de origen genético, y en un futuro para las mejoras genéticas que, en condiciones de equidad y consenso, pudieran autorizarse. La realidad se impone, y es deber del derecho reflejarla fielmente en sus leyes y principios fundamentales. 


\section{BIBLIOGRAFÍA}

- Abellán, F., «Aspectos Bioéticos y legales del Diagnóstico Genético Preimplantacional (DGP)», Revista Iberoamericana de Fertilidad, 2006, vol. 3, nº 2, pp. 123-130.

- Andorno, R., «The Oviedo Convention: A European Legal Framework at the Intersection of Human Rights and Health Law», Journal of International Business and Law, 2005, vol. 2, no 4, pp. 133-143.

- BAltimore, D., ET AL., «A prudent path forward for genomic engineering and germline gene modification», Science, 2015, vol. 348, n 6230, pp. 36-38.

- Bellver Capella, V., «Los Diez Primeros Años del Convenio Europeo sobre Derechos Humanos y Biomedicina: Reflexiones y Valoración», Cuadernos de Bioética, 2008, vol. 19, no 3, pp. 401-421.

- BIOETHIKKOMMISSIONBEIM BUNDESKANZLERAMT, PRÄIMPLANTATIONSDIAGNOSTIK (PID), 2004.

- CAMPS, V., «¿Qué hay de malo en la eugenesia?», Isegoría: Revista de filosofía moral y política, 2002, $n^{\circ} 27$, p. 55-71.

- Cobacho Gómez, J.A. (DIR.), Comentarios a la Ley 14/2006, de 26 de mayo, sobre Técnicas de Reproducción Humana Asistida, Thomson-Aranzadi, Navarra, 2007.

- Comité de BioÉtica de España, Declaración del Comité de Bioética de España sobre la edición genómica en humanos, 16 de enero de 2019.

- De Miguel Beriain, I., Lazcoz, G., «El Convenio de Oviedo, veinte años después de su firma. Algunas sugerencias de enmienda», Rio de Janeiro, 2018, vol. 11, n 1, pp. 445-460.

- De Wert, G., HeINDRYCKX, B., ET AL., «Responsible innovation in human germline gene editing: Background document to the recommendations of ESHG and ESHRE», European Journal of Human Genetics, 2018, vol. 6, no 4, p. 464.

- Egozcue, J., «Preimplantation Social Sexing: A Problem of Proportionality and Decision Making», Journal of Assisted Reproduction and Genetics, 2002, vol. 19, n 9, pp. 440-442.

- FogarTy, N.M.E., ET AL., «Genome editing reveals a role for OCT4 in human embryogenesis», Nature, 2017, vol. 550, nº 7674, pp. 67-73.

- GREELY, H.T., «CRISPR'd babies: human germline genome editing in the 'He Jiankui affair'», Journal of Law and the Biosciences, 2019, vol. $6 \mathrm{n}^{\circ}$ 1, p. 113.

- GONZÁlEZ MORÁN, L., «Implicaciones éticas y jurídicas de las intervenciones de mejora en humanos. Reflexión general», en Romeo Casabona, C.M. (ed.): Más allá de la Salud: intervenciones de mejora en humanos, Comares, Bilbao- Granada 2012, pp. 1-26.

- HANDYside, A.H., ET AL., «Pregnancies from biopsied human preimplantation embryos sexed by Y-specific DNA amplification», Nature, 1990, vol. 344, pp. 768-770.

- HANDYside, A.H., ET AL., «Birth of a normal girl after in vitro fertilization and preimplantation diagnosis testing for cysting fibrosis», The New England Journal of Medicine, 1992, vol. 327, nº 13, pp. 905-909. 
- LANPHIER, E., ET AL., «Don’t edit the human germ line», Nature, 2015, vol. 519, nº 7544, pp. $410-411$.

- LeMA, C., «¿Mejores que quién? Intervenciones de mejora, derechos humanos y discriminación», en Romeo Casabona (ed.): Más allá de la Salud: intervenciones de mejora en humanos, Bilbao-Granada, Comares, 2012, pp. 56-81.

- LIANG, P., XU, Y., ZHANG, X., ET AL., «CRISPR/Cas9-mediated gene editing in human tripronuclear zygotes», Protein Cell, 2015, vol. 6, nº 5, pp. 363-372.

- LOS FINES DE LA MEDicina (traducción al español de The goals of medicine. Setting new priorities. Hastings Cent Rep, 1996, vol. 26, nº 6, supl., pp. S1-S27, $2^{\text {a }}$ ed., Fundació Grifols y Lucá, Barcelona, 2007.

- National Academics of Sciences, Engineering and Medicine. Human Genome Editing. Science, ethics and governance, The National Academies Press, Washington DC, 2017.

- NoguÉs. R.M., «Eugenesia en humanos: delicada e inevitable», Bioética \& Debat, 2009, vol. $15, \mathrm{n}^{\circ} 56$, pp. 6-11.

- Nussbaum, R.L., McInnes, R.R., Wilard, H. F., Thompson \& Thompson Genetics in

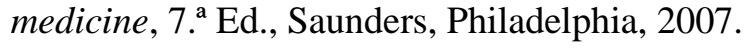

- RAPOSO, V.L., «The convention of human rights and biomedicine revisited: Critical assessment», The International Journal of Human Rights, 2016, vol. 20 nº 8, pp. 1277-1294.

- RENWICK, P.J., ET AL., «Proof of principle and first cases using preimplantation genetic haplotyping-a paradigm shift for embryo diagnosis», Reproductive BioMedicine Online, 2006, vol. 13, no 1, pp. 110-119.

- Romeo Casabona, C.M., «El Bioderecho y la Bioética, un largo camino en común», Revista Iberoamericana de Bioética, 2017, $\mathrm{n}^{\circ} 3$, pp. 1-9, en la página web de la Universidad Pontificia de Comillas: http://revistas.upcomillas.es/index.php/bioetica-revista iberoamericana/article/view/7658/7478 (consultado 20/11/2019).

- SADLER, T.W., Embriología médica de Langman, $12^{\mathrm{a}}$ Edición (edición en español), Wolters Kluwer, Barcelona, 2013.

- SCOTT, R.T., ET AL., «Cleavage-stage biopsy significantly impairs human embryonic implantation potential while blastocyst biopsy does not: a randomized and paired clinical trial». Fertility and Sterility, 2013, vol. 100, nº 3, p. 630.

- Torres-RUIZ, R., «Efficient Recreation of t(11;22) EWSR1-FLI1+ in Human Stem Cells Using CRISPR/Cas9», Stem Cell Reports, 2017, vol. 8, n 5, pp. 1408-1420.

- VeIGA, A., ET AL., «Case report: Twin pregnancy after preimplantation diagnosis for sex selection», Human Reproduction, 1994, vol. 9, n 11, pp. 2156-2159.

- WeweTZER, H., «Alemania: sombras del pasado», The UNESCO courier, 1999, vol. 52, ${ }^{\circ}$ 9, p. 30.

- YAMASHIRO, C., ET AL., «Generation of human oogonia from induced pluripotent stem cells in vitro», Science, 2018, vol. 362, n 6412 , pp. 356-360.

- ZEgers-HoschSCHID, G.D., ET AL., «The International Glossary on Infertility and Fertility Care, 2017», Fertility and Sterility, 2017, vol. 108, n 3, pp. 393-406. 
- ZhANG, J., ET AL., «First live birth using human oocytes reconstituted by spindle nuclear transfer for mitocondrial DNA mutation causing Leigh Syndrome», Fertility and Sterility, 2016, vol. 106, n 3, supl., pp. 375-376. 